\title{
コリオリカを用いた攪拌・混合・洗濯装置の開発*
}

\author{
岩永 正裕 ${ }^{* 1}$, 杉山 博隆 ${ }^{* 2}$, 野田 祐貴 ${ }^{* 2}$ \\ 桐生 芳樹 ${ }^{* 2}$, 原田 和也 ${ }^{* 2}$
}

\section{Development of Stirring Device and Washing Device Using Coriolis Force}

\author{
Masahiro IWANAGA ${ }^{* 1}$, Hirotaka SUGIYAMA, Yuki NODA, Yoshiki KIRYU and Kazuya HARADA \\ ${ }^{* 1}$ Kanagawa Institute of Technology, Dept. of Mechanical Engineering \\ 1030 Shimo-ogino, Atsugi, Kanagawa, 243-0292 Japan
}

\begin{abstract}
Almost stirring devices used blades to stir materials, by the existence of which some efforts were necessary to wash stirring tanks or to exchange materials. So the purpose of this study was to develop devices to stir materials by Coriolis force with no blade. A cylinder rotating around horizontal axis was put on the turntable rotating around vertical axis. The vortex in the rotating cylinder was inclined in the directions upper right or lower right by the effects of Coriolis force. As the speed of turntable was increased, the vortex was collapsed. The phenomena were expected applicable to stirring process and washing process. To examine the effects of stirring process, two types of material were used, that is, undiluted solution of the aqueous paint and washing paste (polyvinyl alcohol). As a result, successful conditions of stirring process became clear with the relations among rotation numbers of capsule, rotation numbers of turntable and diameters of capsule. As an application to cooking, milk shake was cooked at various rotation numbers, and it became clear that it was cooked well when successful conditions were satisfied. As an application to washing, small pieces of the cotton cloth were colored with red ink, and they were washed in a capsule at various rotation numbers, and it became clear that they were washed well, when successful conditions were satisfied.
\end{abstract}

Key Words: Coriolis Force, Stirring Process, Washing Process, Vortex

\section{1. 緒言}

攪汼・混合装置は一般に攪拌羽根を用いて攪拌しており，攪拌槽の清掃や攪拌材料の入れ替えが不便である. 本研 究の目的は, 攪拌羽根を用いないで, コリオリカを用いて容器内の流体を攪拌する装置を開発することである. 同様 の趣旨の先行研究として，木田，後藤らの，歳差運動する球款内ならびに楕円体内の乱流による拡散に関する詳細 な実験的, 数值的研究がある(1)(2).

鉛直軸まわりに回転する回転台の上に水平軸まわりに回転する円筒装置を設置して, 円筒装置内に発生させた強 制渦が，回転台の回転数を上げていくことによって，どのように変化するのかを実験的に調べてきた ${ }^{(3)}$. 回転台の 回転数を上げていくと，円筒内の強制渦は傾きを増し，ついには崩壊する. この渦の崩壊現象を攪拌や洗濯に応用 できないかと考えた ${ }^{(4)}$.

そこで円筒形のカプセル内に白の絵の具と赤の絵の具を満たして，これを擋拌して均一なピンク色にすることが できるか, あるいはカプセル内に赤の絵の具を1滴垂らして残りを洗濯ノリ(ポリビニールアルコール)で満たし, こ の絵の具が均一に擋汼されるかを調べた.

まずカプセルの回転軸を水平から徐々に傾きを増して，攪拌効果がどの角度が最も高いかを調べた.

* 原稿受付 2013 年 4 月 19 日

*1 正員, 神奈川工科大学 (厂243-0292 神奈川県厚木市下荻野 1030)

*2 神奈川工科大学 大学院

E-mail: iwanaga@me.kanagawa-it.ac.jp 
次にカプセルの回転数と回転台の回転数を変化させて, どのような場合に攪拌効果があるかを調べた. どのように して攪拌が行われるかを知るために，射影法 ${ }^{(5)}$ によってシミュレーションを行い，流体粒子の軌跡を調べた.

食品加工への応用の一例として, ミルクセーキを作成して, ミルクセーキの出来栄えとカプセルの回転数と回転台 の回転数の関係を調べた. 洗濯行程への応用として, カプセルの中に赤インクで染めた白い木綿布を入れて, 洗濯効 果とカプセルの回転数と回転台の回転数の関係を調べた.

\section{2. 実験装置}

実験装置 1 と実験装置 2 の 2 つ実験装置を制作して使用した．図 1 に示寸実験装置 1 は，回転場を作る回転台 の直径は約 $450 \mathrm{~mm}$ で，鋁直軸まわりに回転する，その回転台の上に角度 $\theta$ を調節できる台を設置して，その台の上 に AC モータを設置し, カプセルはこのモータによって回転する. モータにはスリップリングを介して電圧を供給し, 外部でスライダックにより電圧を変化させることにより，モータの回転数を制御した. 反射テープによる反射光を フォトトランジスターを用いて電気信号に変え，この信号をスリップリングを介して外部で計測して，カプセルの 回転数を知ることができる. 回転台の回転数は $200 \mathrm{rpm}$ 以下，カプセルの回転数は $1300 \mathrm{rpm}$ 以下で実験を行った.

より回転台の回転数が大きな領域で実験を行うために, 図 2 に示寸実験装置 2 を制作几て使用した. 実験装置 2 は直径約 $220 \mathrm{~mm}$ の回転台の上で，カプセルを水平軸回りに回転させた. 回転台の回転数は $700 \mathrm{rpm}$ 以下，カプセルの 回転数は $1100 \mathrm{rpm}$ 以下で実験を行った．カプセルを回転させるプーリーに強力な永久磁石を埋め込み，地上に固定 したコイルにこの磁石が近づくことにより発生する電流の変化を計測してカプセルの回転数を求めた.

カプセルの角速度を $\omega$, 回転台の角速度を $\Omega$ とする.
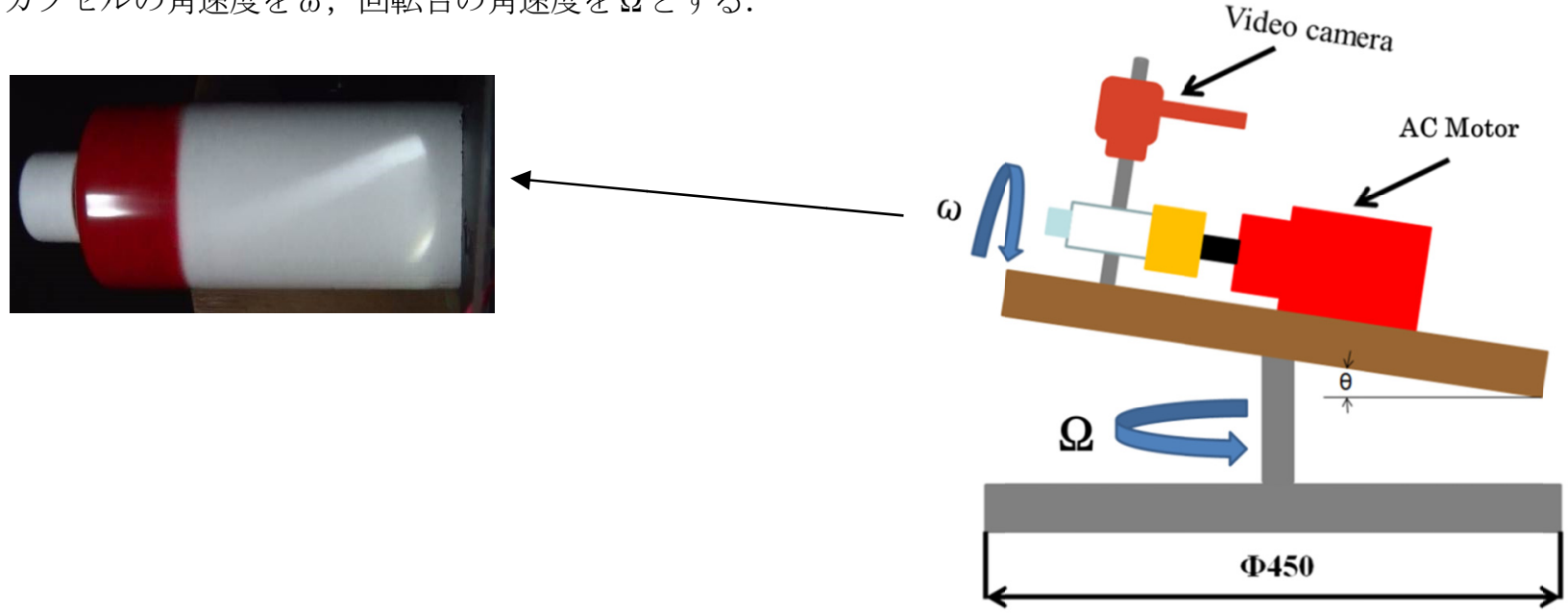

Fig.1 Schematic diagram of apparatus No.1

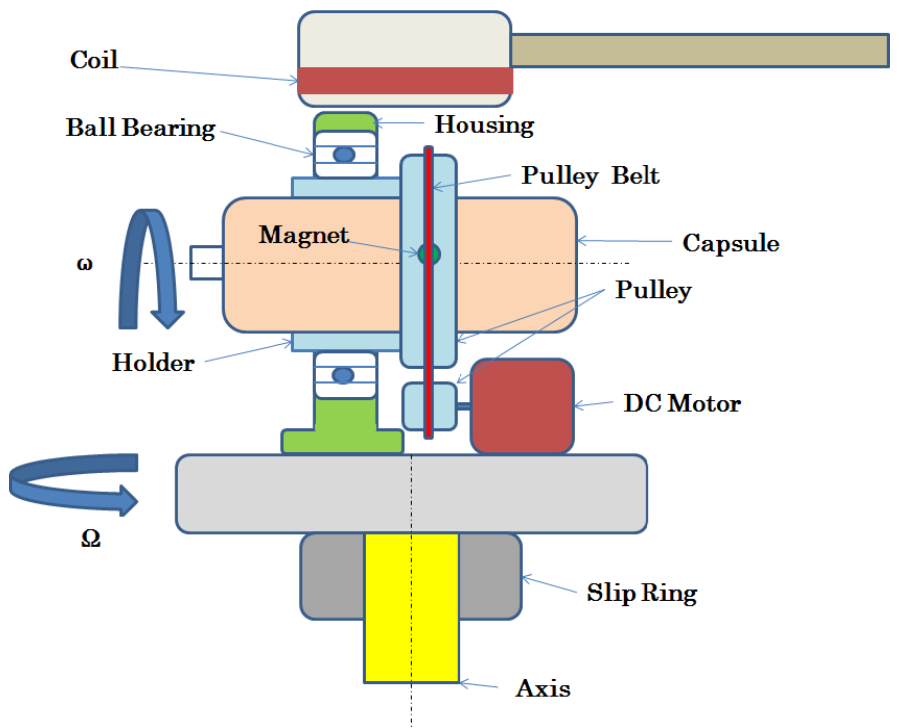

Fig.2 Schematic diagram of apparatus No.2 


\section{3. 実験結果}

\section{$3 \cdot 1$ カプセル回転軸の角度の影響}

実験装置 1 と内径 $52 \mathrm{~mm}$ ，長さ $140 \mathrm{~mm}$ のカプセルを用い，カプセル内には白の絵の具を 8 割，赤の絵の具を 2 割満 たした. 赤の絵の具は比重 1.13 , 粘度 $4 \mathrm{~Pa} ・ \mathrm{~s}$, 白の絵の具は比重 1.44 , 粘度 $7 \mathrm{~Pa} ・ \mathrm{~s}$ である. 回転台の上にビデオ カメラを設置して，時々刻々のカプセル内の色の変化を記録した．実験は暗室の中で行い，回転台に固定したライ トでカプセルを照らしながら撮影を行った．回転台の回転数は約 $150 \mathrm{rpm} ，$ カプセルの回転数は 800 900 rpm になる ように制御して実験を行った。

色の判定はビデオ画像をコンピュータに取り込んで, 各点の色を 3 原色（赤，緑，青）に分解して0〜255 の值 で記録する．白色光の元でならば，赤を 1 ，白を 0 とする赤の度合いに変換するには

赤の度合い $=\{$ 赤/ $($ 赤十緑十青 $)-1 / 3\} \times 3 / 2$

で与えられる. 投下光の白色光からのズレを補正するために，攪拌前の白の部分における赤の度合いと，赤の部 分における赤の度合いを予め求めておいて,

（赤の度合い一白部の赤の度合い）/（赤部の赤の度合い一白部の赤の度合い）

として，攪拌過程の各点の赤の度合いを算出した。

図 3 は横軸にカプセルの軸方向位置をカプセルの長さで無次元化した值をとり, 縦軸に赤の度合いをとった. 1 分毎のカプセルの赤の色の度合いの分布の変化を示している．攪拌前には図 1 に示すように，赤と白の絵の具 がはっきりと分離しているが，6 分後には図 4 に示すように均一なピンク色に混ざっていることがわかる.この カプセルを冷凍した上で切断して内部を観察した結果，内部まで均一に擋拌されていることが確かめられた.

図 5〜図 8 はカプセルの回転軸の角度 $\theta$ を $15^{\circ} \sim 75^{\circ}$ に傾けたときの, 図 3 と同様の結果である. いずれの場合 も 6 分経っても均一なピンク色にならずにムラがあることがわかる.

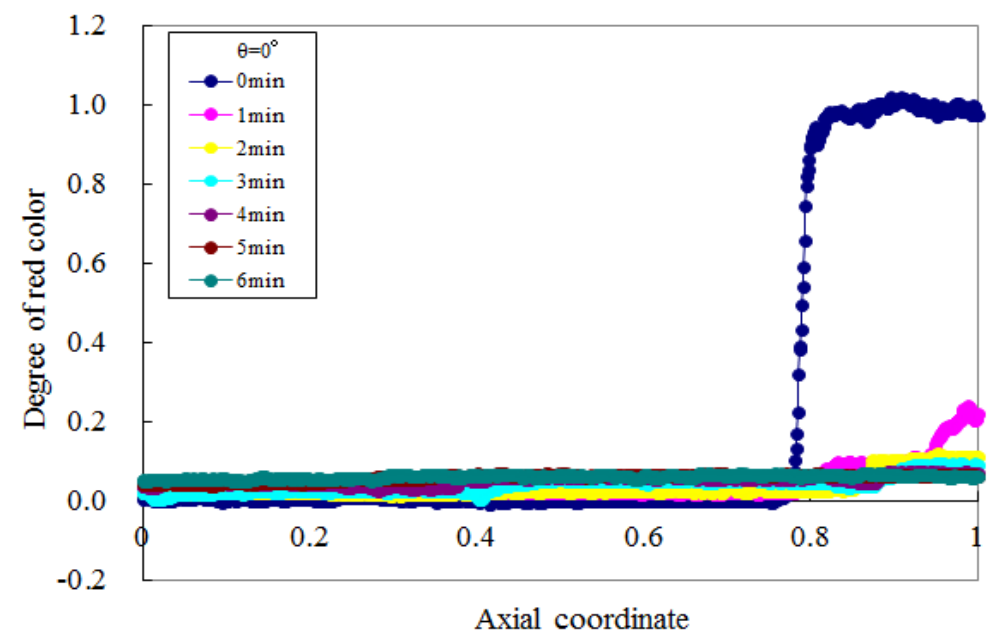

Fig.3 Distribution of $\operatorname{Red} \operatorname{Color}\left(\theta=0^{\circ}\right)$

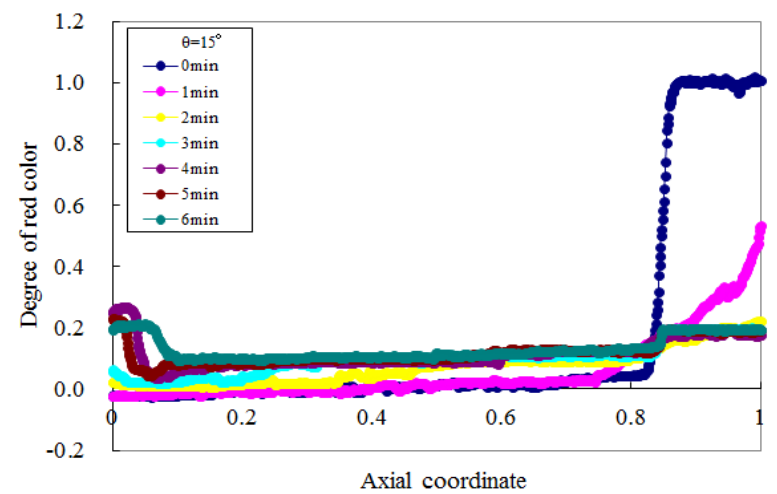

Fig.5 Distribution of $\operatorname{Red} \operatorname{Color}\left(\theta=15^{\circ}\right)$

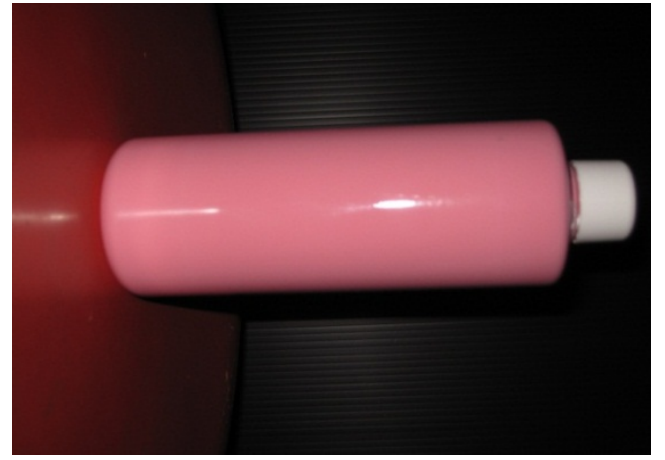

Fig.4 Photo of the Capsule after stirring

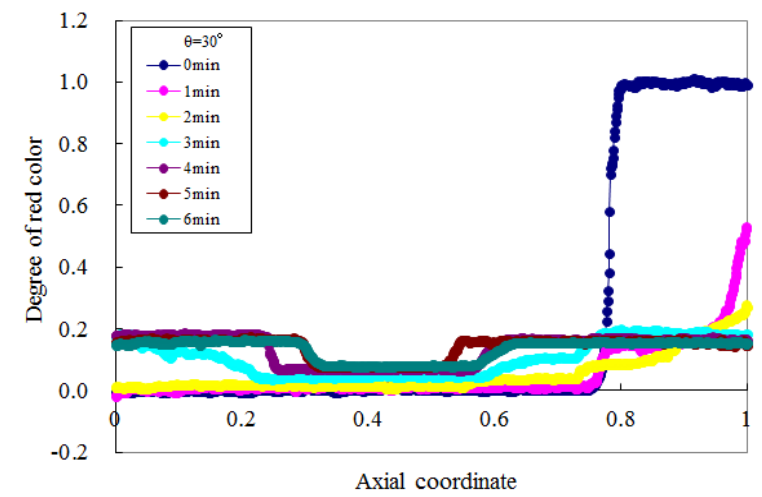

Fig.6 Distribution of $\operatorname{Red} \operatorname{Color}\left(\theta=30^{\circ}\right)$ 


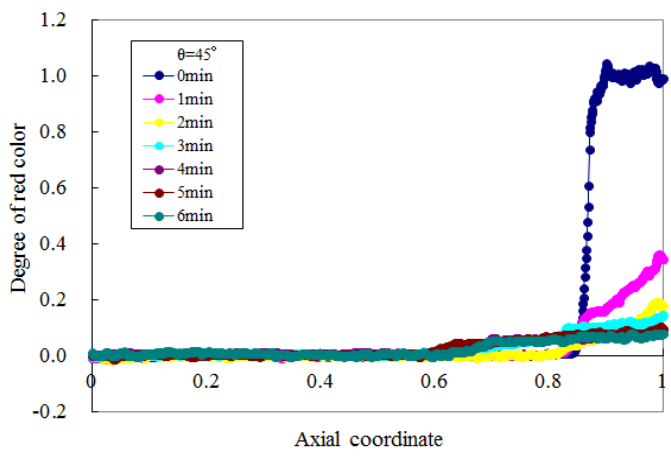

Fig.7 Distribution of $\operatorname{Red} \operatorname{Color}\left(\theta=45^{\circ}\right)$

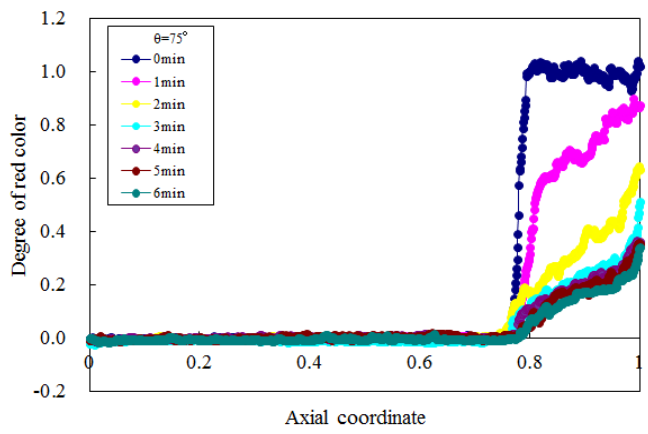

Fig.8 Distribution of $\operatorname{Red} \operatorname{Color}\left(\theta=7^{\circ}\right)$

図 9 は縦軸に攪拌途中のカプセル中の色の均一度をとり, 横軸に経過時間をとった. 縦軸の值は標準偏差 $\sigma$ を

$$
\sigma=\sqrt{\frac{\sum\left(\text { 赤の度合しᄂ赤の度合いの平均值 }{ }^{2}\right.}{N}}
$$

均一度 $=\sigma /$ 赤の度合いの平均值

として算出した. 值が小さいほど均一である. カプセルの回転軸の傾きが $45^{\circ}$ 以上の場合，これ以上攪䢁を続けて も均一化は望めそうにない. $30^{\circ}$ 以下の角度では，攪找を続ければより均一化される様相を呈しているが，角度 $0^{\circ}$ の攪拌能力が顕著である.

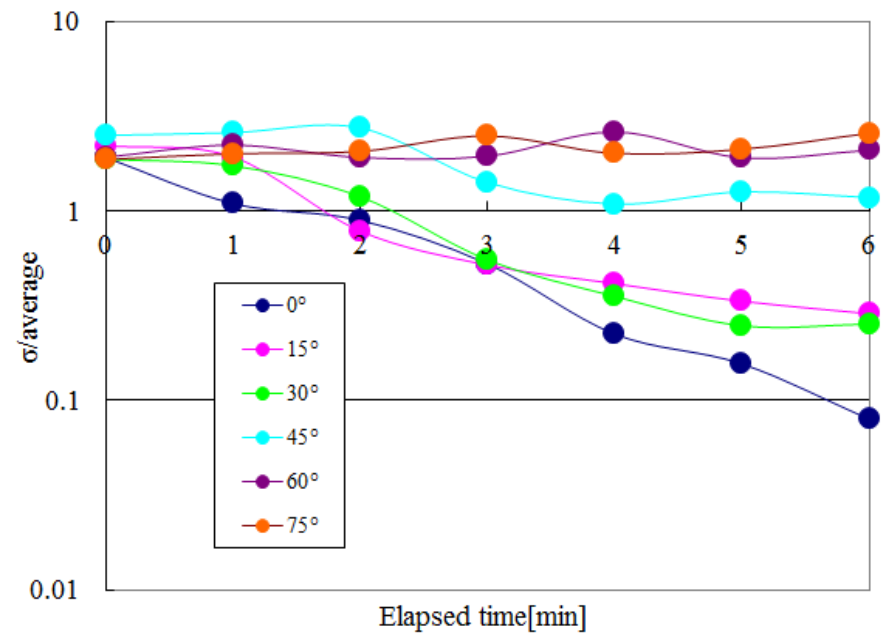

Fig.9 Influence of inclination of axis of capsule

\section{$3 \cdot 2$ 擋拌条件}

図 10 は縦軸にカプセルの回転数を取り，横軸に回転台の回転数をとった．カプセルの回転軸は水平である. 印は攪拌が成功した実験点，×印は攪拌が不完全な実験点を示す.実験装置 1 (図 1) を用いて実験を行い，内径 $52 \mathrm{~mm}$ ，長さ $140 \mathrm{~mm}$ のカプセルを用いた. 赤印は 3.1 と同様に，カプセル内の 8 割を白の絵の具， 2 割を赤の絵の具 で満たした場合であり，青印はカプセルの中に 4Pa・s の赤の絵の具を一滴たらし，残りを粘度が 0.9Pa・s の透明 な洗濯ノリ（ポリビニールアルコール）で満たした場合である. 攪拌の成功，失敗の判定は，6分以上回転させた 後に, 目視によりカプセル内が均一であるか否かを判定した. 赤印, 青印で粘度が大きく異なるにもかかわらず, 攪拌の成功，失敗の領域はほぼ一致していることがわかる.

図 11 は図 10 と同様の図であるが，カプセルの大きさを次の 5 種類に変化させて調べた.

(1) カプセル内径 : $34 \mathrm{~mm}$, カプセル長さ : $64 \mathrm{~mm}$ ，アスペクト比 : 1.9 (50ml)

(2) カプセル内径 : $39 \mathrm{~mm}$ ，カプセル長さ : $96.5 \mathrm{~mm}$ ，アスペクト比 : 2.5 (100ml)

(3) カプセル内径 : $45 \mathrm{~mm}$, カプセル長さ : $128 \mathrm{~mm}$ ，アスペクト比 : 2.8 (200ml)

(4) カプセル内径 : $52 \mathrm{~mm}$, カプセル長さ : $140 \mathrm{~mm}$, アスペクト比 : 2.7 (300ml)

(5) カプセル内径 : $63 \mathrm{~mm}$, カプセル長さ : $165 \mathrm{~mm}$, アスペクト比 : 2.6 (500ml) 
実験は実験装置 2（図 2）で行い，カプセルの中には，4Pa・s の赤の絵の具を一滴たらし，残りを粘度が $0.9 \mathrm{~Pa} ・ \mathrm{~s}$ の透明な洗濯ノリ（ポリビニールアルコール）で満たした． 6 分以上回転させた後に，目視によりカプセル内が均 一であるか否かを判定した．図11より攪拌を成功させるには次の条件が必要であることがわかった.

（1）カプセルの大きさによらず，カプセルの回転数が 400rpm 以上であること.

（2） カプセルの大きさ毎に回転台の回転数の下限が存在して，その值はカプセルが小さくなるほど大きく なる.

（3）カプセルの大きさ毎に原点を通る直線が存在して，その直線よりも下方の領域であること．この直線 の傾き $\omega / \Omega$ は，慣性力とコリオリカの比を表すロスビー数を表す．すなわち，カプセル毎に上限の ロスビー数が存在し，この值はカプセルが小さくなるほど小さくなる.

以上を表にまとめたものが, 表 1 である. カプセルの大きさが大きいほど, 攪找成功の領域は広いことがわかる. カプセル内径を横軸にとってグラフ表示したものが，図 12〜図 14であり，上記（1）〜（3）の条件を表して いる．それぞれ縦軸にカプセルの回転数の下限值，回転台の回転数の下限值， $\omega / \Omega$ をとった.

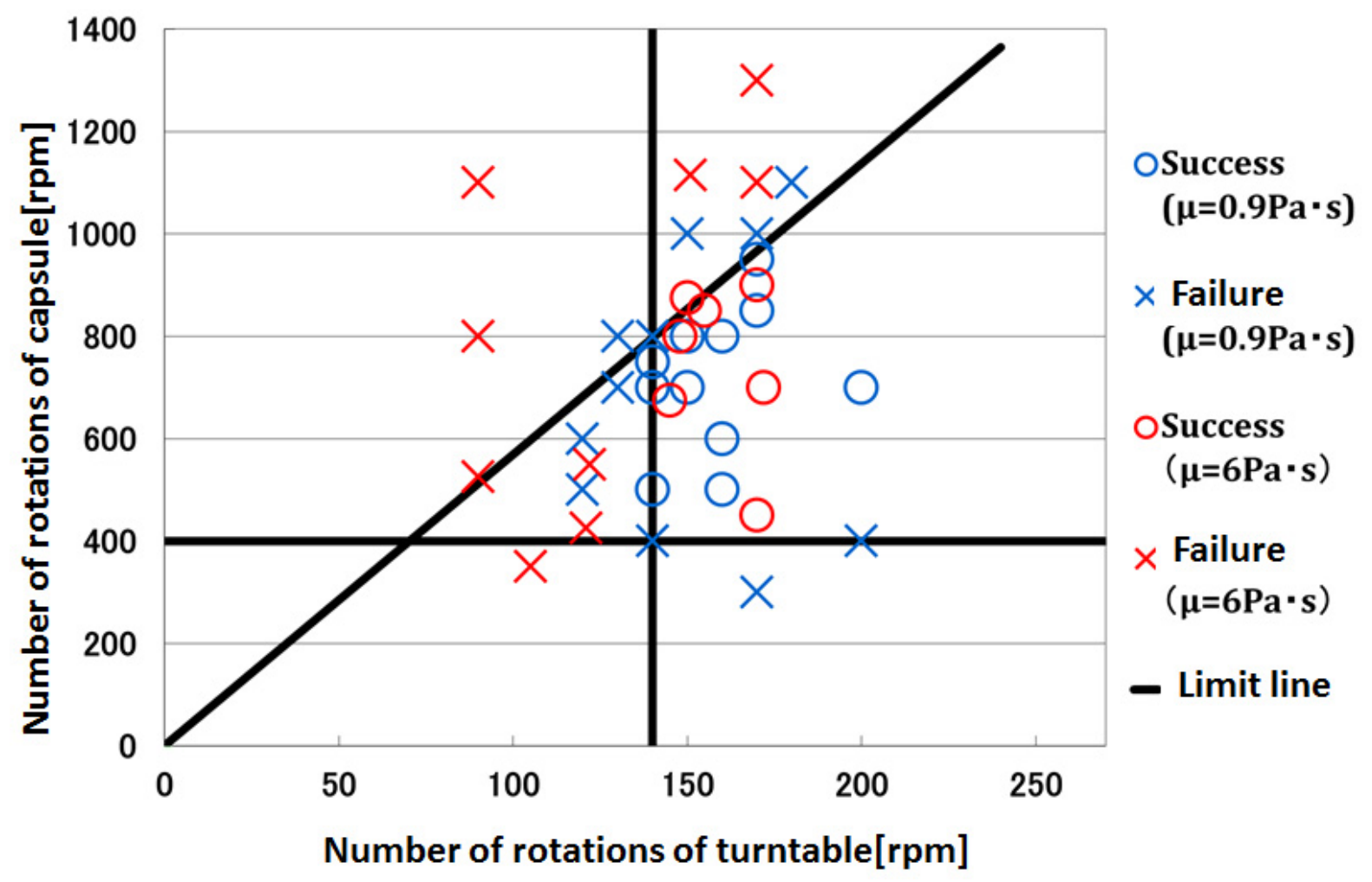

Fig.10 Successful conditions of stirring process for two types of test material with different viscosities 


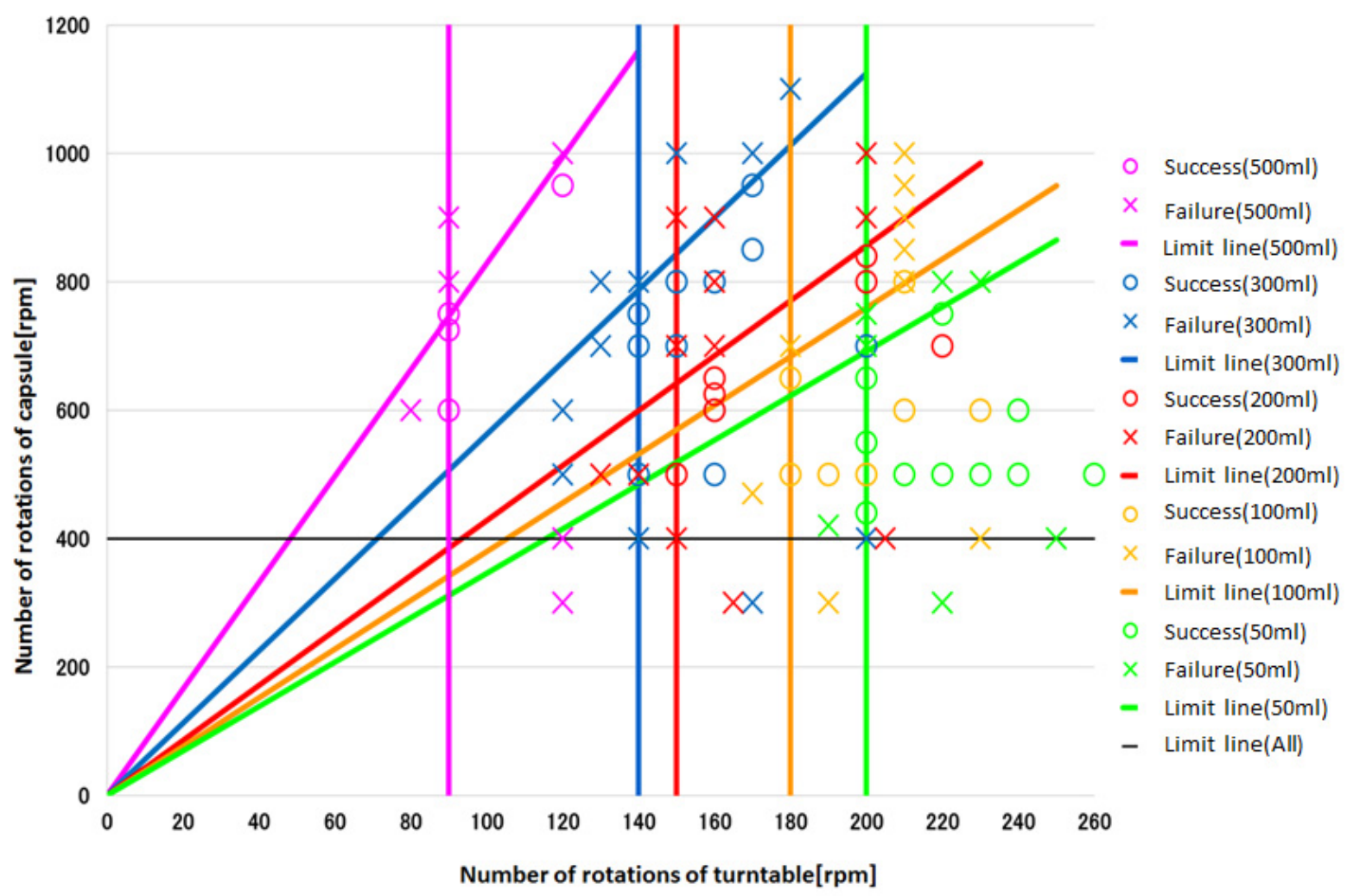

Fig.11 Successful conditions of stirring process for several types of capsules with different diameters

Table1 Successful Conditions of stirring process

\begin{tabular}{|c|c|c|c|c|c|}
\hline Inner capacity & $500 \mathrm{ml}$ & $300 \mathrm{ml}$ & $200 \mathrm{ml}$ & $100 \mathrm{ml}$ & $50 \mathrm{ml}$ \\
\hline Diameter & $63 \mathrm{~mm}$ & $52 \mathrm{~mm}$ & $45 \mathrm{~mm}$ & $39 \mathrm{~mm}$ & $34 \mathrm{~mm}$ \\
\hline$\omega / \Omega$ & 8.28 and less & 5.6 and 1 ess & 4. 28 and less & 3.8 and less & 3.46 and 1 ess \\
\hline $\begin{array}{c}\text { Number of rotations } \\
\text { of turntable }\end{array}$ & $\begin{array}{c}90 \text { rpm and } \\
\text { over }\end{array}$ & $\begin{array}{l}140 \begin{array}{l}\text { rpm and } \\
\text { over }\end{array} \\
\text { a }\end{array}$ & $\begin{array}{l}150 \begin{array}{l}\text { rpm and } \\
\text { over }\end{array}\end{array}$ & $\begin{array}{l}180 \begin{array}{l}\text { rpm and } \\
\text { over }\end{array}\end{array}$ & $\begin{array}{l}200 \mathrm{rpm} \text { and } \\
\text { over }\end{array}$ \\
\hline $\begin{array}{c}\text { Number of rotations } \\
\text { of capsule }\end{array}$ & \multicolumn{5}{|c|}{ 400rpm and over } \\
\hline viscosity & \multicolumn{5}{|c|}{ From $0.9 \mathrm{~Pa} \cdot \mathrm{s}$ to $6 \mathrm{~Pa} \cdot \mathrm{s}$} \\
\hline
\end{tabular}

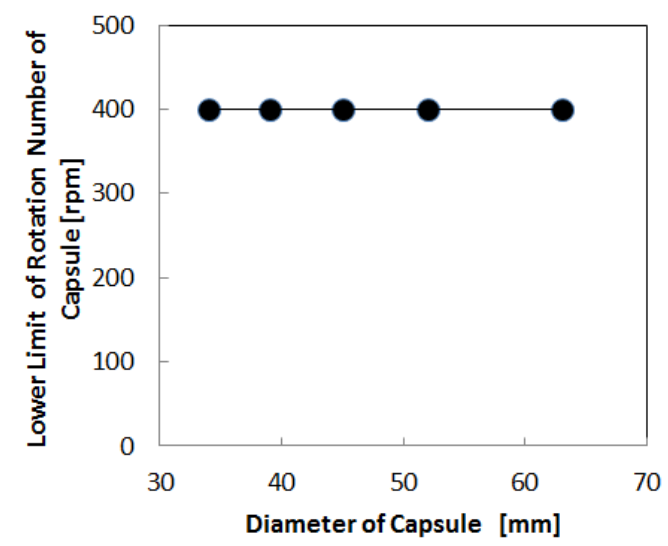

Fig.12 Lower limit of rotation number of capsule

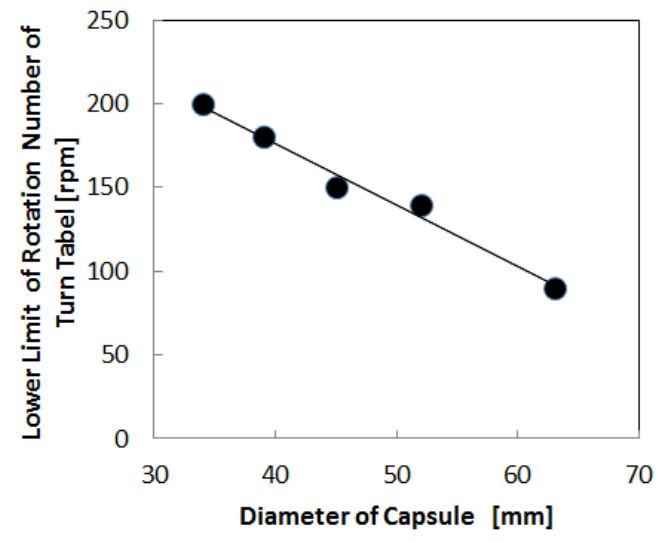

Fig.13 Lower limit of rotation number of turntable 


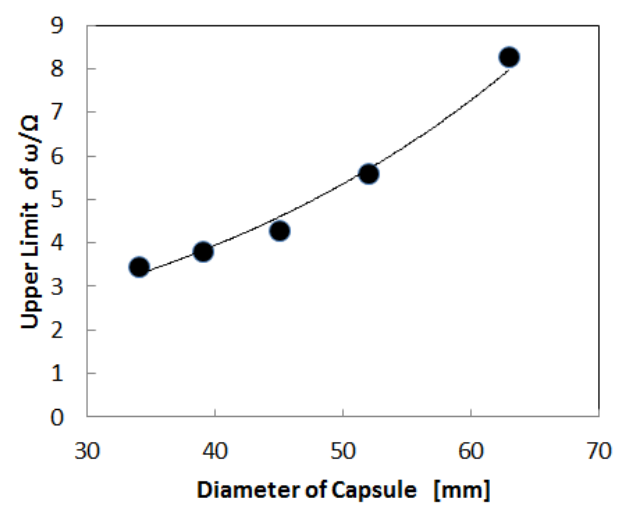

\section{Fig.14 Upper limit of value of $\omega / \Omega$}

\section{$3 \cdot 3$ シミュレーション}

図 15 は射影法 ${ }^{(5)}$ 用いて， $\omega / \Omega=3.3$ ，カプセルの半径を代表長さとし，カプセルの外周速を代表速度とした レイノルズ数が 100 の場合のカプセル内部の流体の動きを調べたもので，速度分布と流体粒子の軌跡を 3 方向か ら見た図である．白い領域はカプセルの軸方向速度が負の領域，灰色の領域は正の領域で，○印は渦中心位置を 示寸．流体粒子の軌跡は暗い点からから明るい点に向かって流体粒子が移動することを示しており，カプセル中 のかなり広い範囲を流体粒子が動き回ることがわかる。このような過程で攪拌が行われると考えられる.

図 16 は実験装置 1 を用いて, 内径 $52 \mathrm{~mm}$, 長さ $140 \mathrm{~mm}$ のカプセルに $4 \mathrm{~Pa} ・ \mathrm{~s}$ の赤の絵の具を一滴たらし, 残りを粘 度が $0.9 \mathrm{~Pa} ・ \mathrm{~s}$ の透明な洗濯ノリ（ポリビニールアルコール）で両たして，その内部の時間的な変化をビデオ撮影し たときの一瞬の画像である. シミュレーション結果と類似した渦芯のうねりが観察された.

\section{$3 \cdot 4$ 食品加エへの応用（ミルクセーキ）}

食品加工一の応用の手始めとして，ミルクセーキを作ることを試みた．直径 $65 \mathrm{~mm}$ ，長さ $165 \mathrm{~mm}$ ，容量 $500 \mathrm{ml}$ のカ プセルを水平軸周りに回転させる. 回転台の回転数は 70〜200 rpm，カプセルの回転数は 300 900 rpm である. カプ セルにミルクセーキの材料となる牛乳 $300 \mathrm{ml}$, 卵の黄身 2 個, 砂糖 $36 \mathrm{~g}$ を入れ, 残りは空気で満たし 5 分間回転させ る. よく擋找されたミルクセーキは美味しく, ネットリとした食感で粘度が高いことから, 粘度計測によりその完成

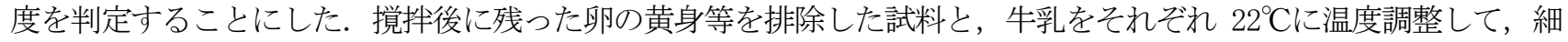
管法に基づく粘度計で粘度を計測した。

図 17 中の各印はミルクセーキの粘度と牛乳の粘度の比によって分類されており，この值が大きいほど攪拌効果が 大きく, 美味しいミルクセーキが作れたことになる. 擋拌効果が大きい領域で粘度が高く, その中でも回転数が高い ほど擋汼効果が大きいことがわかる.

\section{$3 \cdot 5$ 洗濯効果}

三角巾をカットした $80 \mathrm{~mm} \times 80 \mathrm{~mm}$ の木綿布をテストピースとして，万年筆用の赤色インクと水を $1: 100$ の割合で混 ぜた液に浸けた後に乾燥させた。この布枚を水 $500 \mathrm{ml}$, 洗剤 $1 \mathrm{~g}$ とともに直径 $65 \mathrm{~mm}$, 長さ $165 \mathrm{~mm}$, 容量 $500 \mathrm{ml}$ のカプ セルに入れて, 回転台の回転数 $700 \mathrm{rpm}$ 以下, カプセルの回転数 $700 \mathrm{rpm}$ 以下で 1 分間回転させた. 時間を 1 分間に限 ったのは, 洗濯効果が強力で, これ以上攪挥を続けると, 回転条件による色の変化が見られなくなるためである. こ の布を 1 日乾燥させた後に, スキャナーで画像として取り込み, Visual Basic で作成した画像解析プログラムで解 析した. 各点の色を赤, 緑, 青に分解して 0 ～255 の数值として計測し, 赤の数值が, 緑と青の数值の平均值に対し て何倍であるかで, 赤色の濃さを表した. この值が 1 のとき赤の残留度は 0 で, この值が大きくなるほど赤の残留度 が多いことを表す。

図 18 の各印は赤色の濃さを表す数值により分類されており，この值が 1 に近いほど赤色が薄く洗濯効果が大きい ことを表す. 摚汼効果が大きい領域で洗濯効果が大きく, その中でも回転数が大きいほど洗濯効果が大きいことがわ かる. 

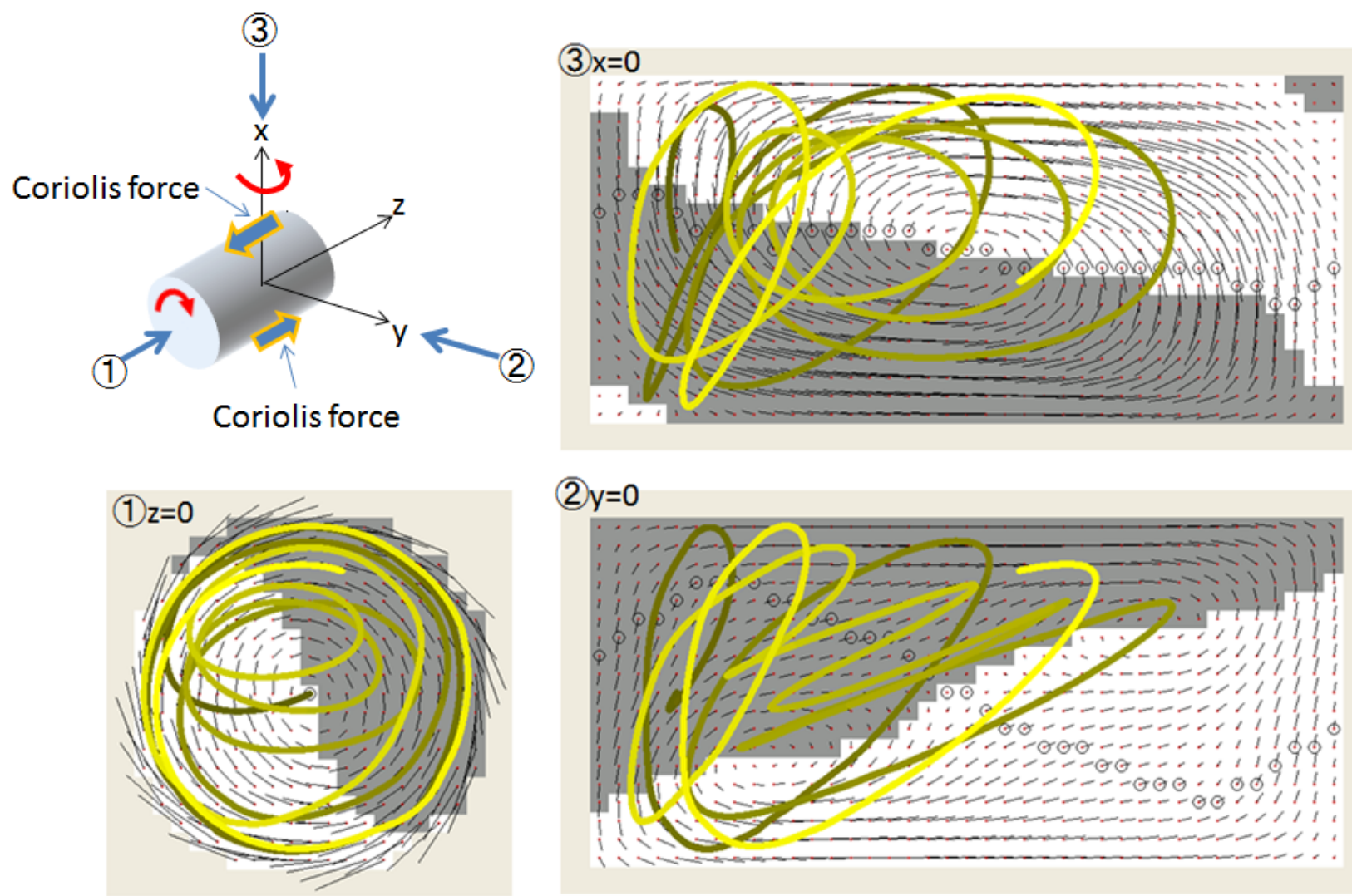

Fig.15 Flow pattern when aspect ratio is $2.0, \omega / \Omega$ is 3.3 , Reynolds number is 100

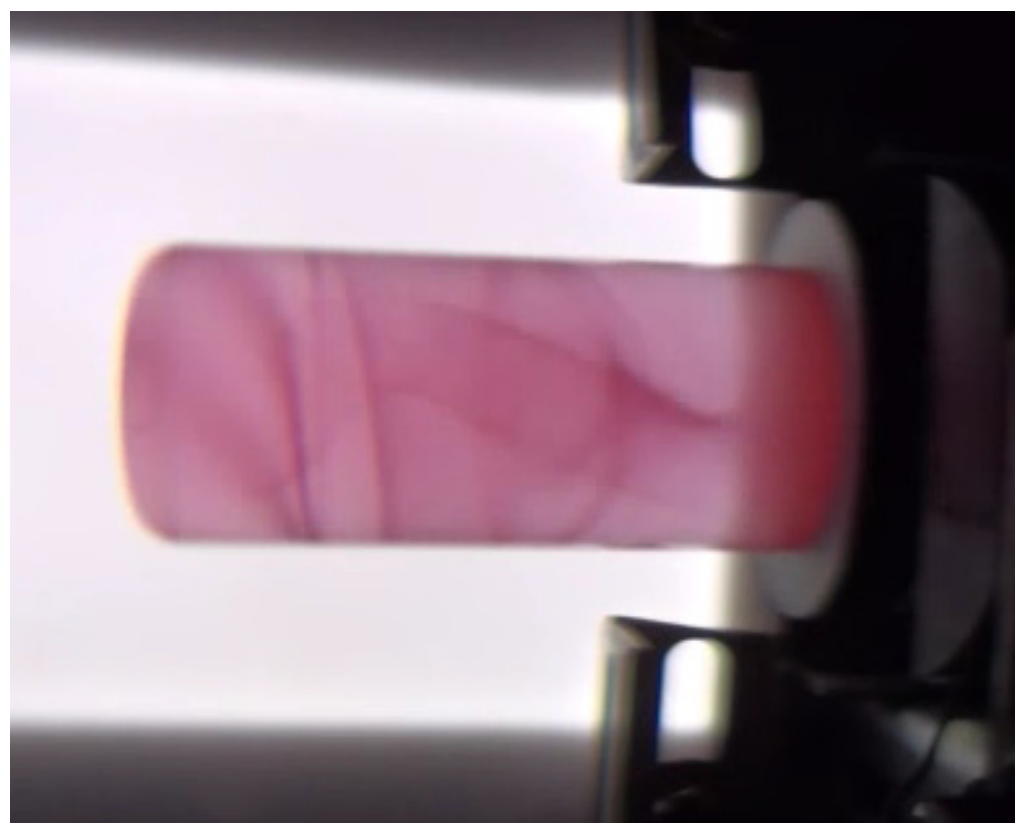

Fig.16 Photo of flow pattern in a capsule 


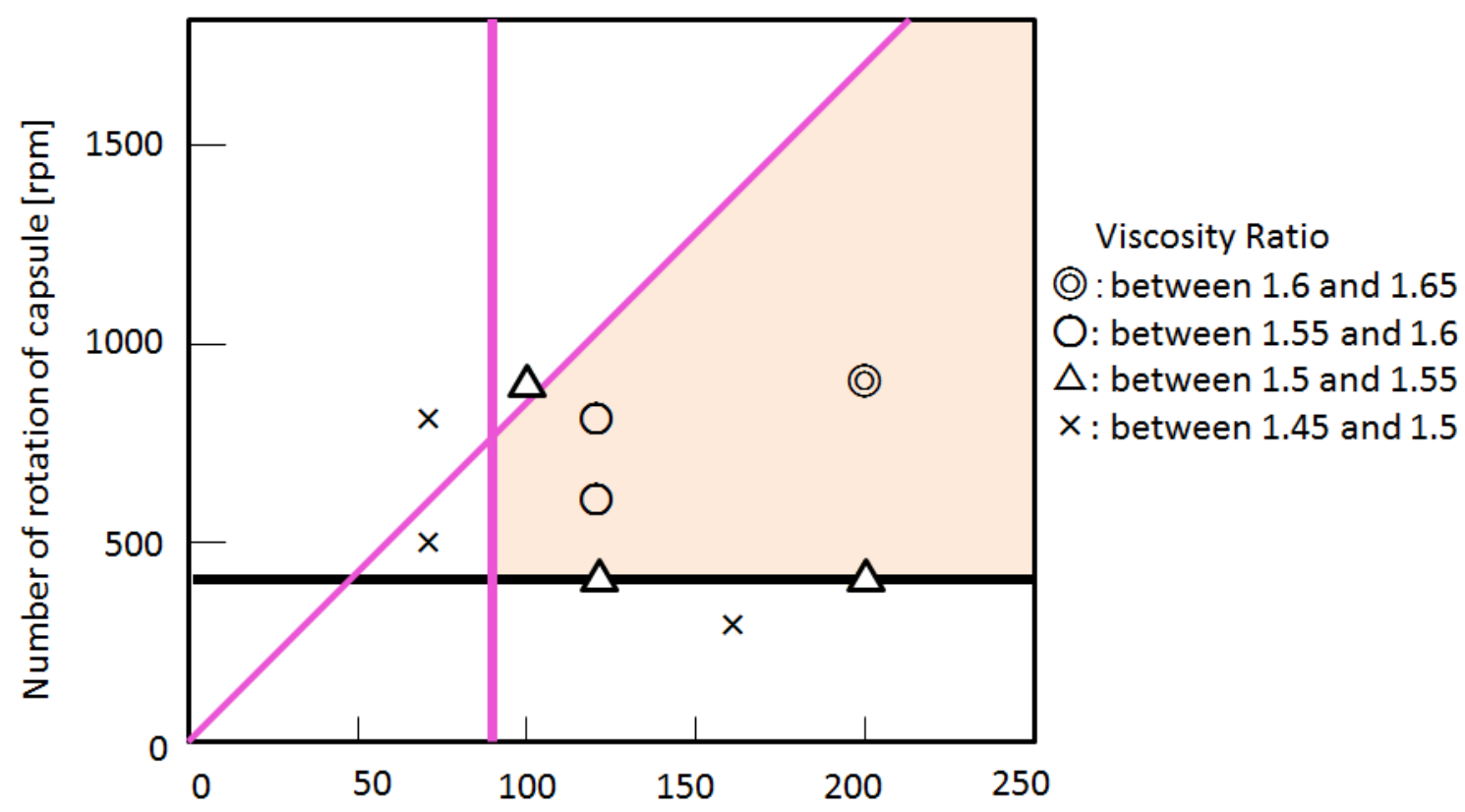

Number of rotation of turntable [rpm]

Fig.17 Successful conditions for cooking milk shake

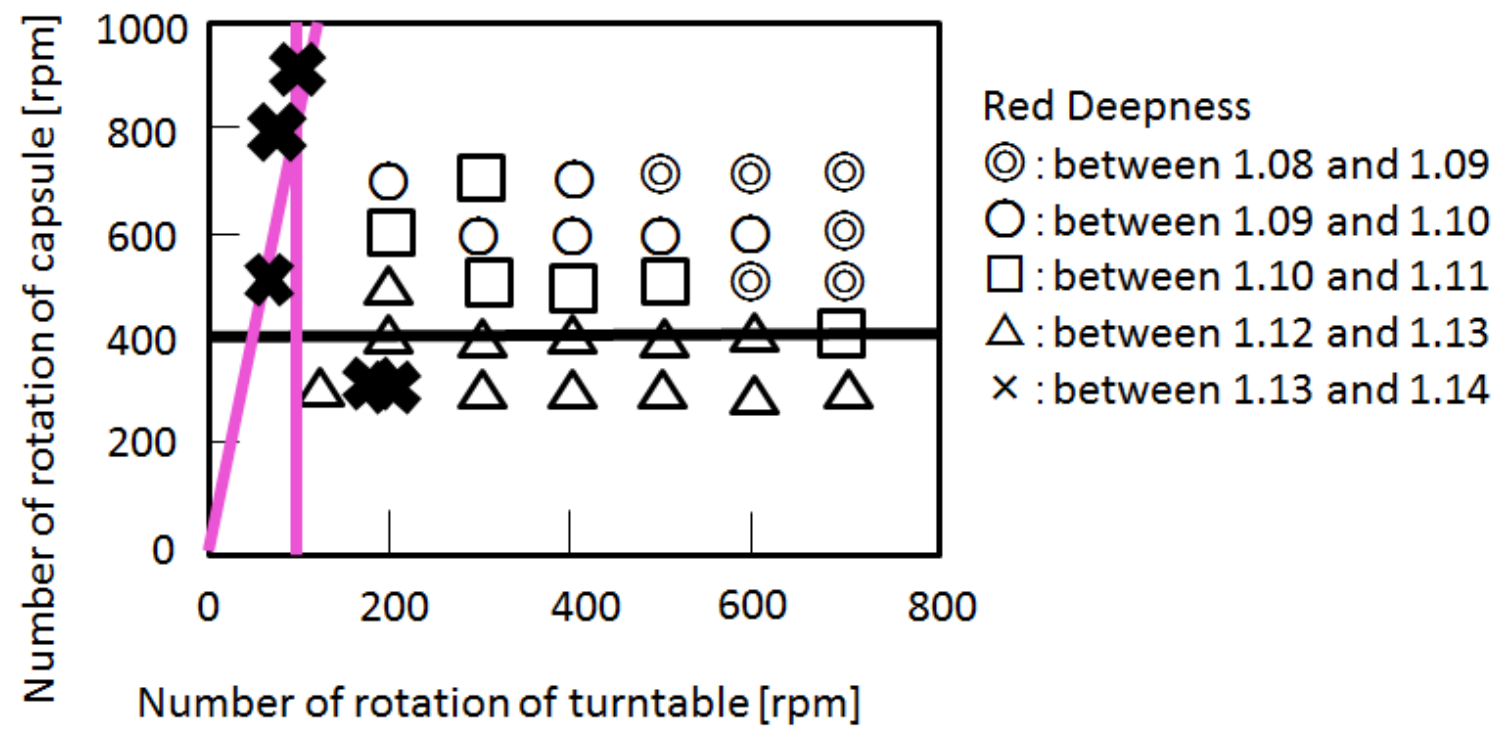

Fig.18 Successful condition for washing

\section{4. 結言}

鈶直軸まわりに回転する回転台の上に，回転する円筒形のカプセルを設置して，カプセル内の流体の攪䢁効果につ いて調べて次のような結果を得た. なお力プセルは内径が $34 \mathrm{~mm} ６ 4 \mathrm{~mm}$ の範囲の数種について実験を行った.

1） カプセルの回転軸の角度を水平から $0^{\circ} \sim 75^{\circ}$ の範囲で変化させて攪挥効果を調べた. その結果水平（回転台 の回転軸と垂直）の場合に，最も攪挥効果が大きいことが確かめられた.

2） カプセルの回転数と回転台の回転数を変化させて, 均一に撹拌できる条件を調べた. 粘度が $6 \mathrm{~Pa} ・ \mathrm{~s}$ と $0.9 \mathrm{~Pa} ・$ s の試料について調べ，その結果粘度の大きさによらず，十分な攪拌を得るためには次のような条件が必要で あることがわかった. 
a）カプセルの内径によらず，カプセルの回転数が 400rpm 以上であること.

b）回転台の回転数の下限が存在し，その值はカプセルの内径が小さくなるほど大きくなる.

c）カプセルの回転数と回転台の回転数の比の值に上限があり，この值はカプセルの内径が小さくなるほど 小さくなる.

3）射影法によってシミュレーションを行い，流体粒子の軌跡を調べ，その軌跡が複雑で攪拌効果をもたらすこと を確かめた。

4）攪拌効果の実例としてミルクセーキを作成して，その出来栄えを，粘度を計測することにより調べた結果，2） の攪拌条件領域内で，回転台の回転数が大きいほど，良い出来栄えであることがわかった。

5）洗濯効果の検証として，赤インクで染めた白い木綿布を入れて，洗濯効果を調べた結果，2）の攪找条件領域 内で，回転台の回転数が大きいほど，洗濯効果が高いことがわかった.

以上のことより, 攪拌羽根を用いないで，コリオリカを用いて容器内の流体を攪拌寸る装置を開発することででき て，食品加工や，洗濯機として利用できることを確かめた.

\section{謝 辞}

本研究の遂行に当たっては神奈川工科大学卒業研究生菊地悠, 佐藤洋平, 里中俊介, 神尾健太, 高志岩, 岩本 健人, 小西邦尚, 酒井直人, 林和人, 西原幸太郎, 村上慧, 中川皓天, 関 雄介の諸氏の協力を得た. 卒業研究 生近藤亜沙美氏は食品加工への応用としてミルクセーキを提案された．ここに記して謝意を表する.

\section{付録＼cjkstart無次元数ならびに実験結果の考察}

木田，後藤らは，現象を $\Omega / \omega （$ 歳差強さ）と $\rho \omega \mathrm{a}^{2} / \mu$ （レイノルズ数）の無次元数で整理している ${ }^{(1)}$ (2). ここに a は円筒半径である.

改めてどのような無次元数が，攪拌条件に関する本実験結果を説明するのに適しているかを考察する．諸物理 量の代表值を以下のように見積もる．Lはカプセルの軸方向の長さである.

代表速度 $=\mathrm{a} \omega ，$ 代表面積 $=\mathrm{aL} ，$ 代表体積 $=\mathrm{a}^{2} \mathrm{~L}$

代表せん断力 $=(\mu \mathrm{a} \omega / \mathrm{a}) \quad \mathrm{aL}=\mu \omega \mathrm{aL}$ （代表せん断応力と代表面積の積）

代表慣性力 $=\rho(\mathrm{a} \omega)^{2} \mathrm{aL}=\rho \omega^{2} \mathrm{a}^{3} \mathrm{~L} \quad$ （代表面積を単位時間に通過する運動量）

代表コリオリカ $=(\rho \mathrm{a} \omega \Omega) \mathrm{a}^{2} \mathrm{~L}=\rho \omega \Omega \mathrm{a}^{3} \mathrm{~L}$ (単位体積の流体に加わるコリオリカの代表值と代表体積の積)

これらを用いて定義される無次元数は以下の 3 つである.

レイノルズ数: 慣性力と粘性力の比 $\quad \operatorname{Re}=\rho \omega^{2} \mathrm{a}^{3} \mathrm{~L} /(\mu \omega \mathrm{aL})=\rho \omega \mathrm{a}^{2} / \mu$.

ロスビー数 : 慣性力とコリオリカの比 $\mathrm{Ro}=\rho \omega^{2} \mathrm{a}^{3} \mathrm{~L} /\left(\rho \omega \Omega \mathrm{a}^{3} \mathrm{~L}\right)=\omega / \Omega$ (木田, 後藤らの歳差強さの逆数とな っている）.

エクマン数 : 粘性力とコリオリカの比 $\mathrm{Ek}=\mu \omega \mathrm{aL} /\left(\rho \omega \Omega \mathrm{a}^{3} \mathrm{~L}\right)=\mu /\left(\rho \Omega \mathrm{a}^{2}\right)$.

$\mathrm{Re}=\mathrm{Ro} / \mathrm{Ek}$ の関係がある. 図 10 において粘度が大きく異なる 2 つの流体に対して，攪找条件が一致して いるので, 粘度を含むレイノルズ数またはエクマン数を用いて実験結果を整理することは難しいと考えられる.

次に遠心力とコリオリカの比を表す無次元数を考える.

水平軸周りの回転による代表遠心力 $=\left(\rho \mathrm{a} \omega^{2}\right) \quad \mathrm{a}^{2} \mathrm{~L}=\rho \omega^{2} \mathrm{a}^{3} \mathrm{~L}$

鉛直軸周りの回転による代表遠心力 $=\left(\rho \mathrm{L} \Omega^{2}\right) \quad \mathrm{a}^{2} \mathrm{~L}=\rho \Omega^{2} \mathrm{a}^{2} \mathrm{~L}^{2}$

水平軸周りの回転による遠心力とコリオリカの比 $=\omega / \Omega$

となり, ロスビー数に一致する.

鉛直軸周りの回転による遠心力とコリオリカの比 $=(\Omega / \omega) \quad(\mathrm{L} / \mathrm{a})$

の值がある值 $\chi$ よりも小さくなる必要があるとすると, $(\Omega / \omega)(\mathrm{L} / \mathrm{a})<\chi$ すなわち $\omega / \Omega>(\mathrm{L} / \mathrm{a})(1 / \chi)$ となって, ロスビー数の下限が存在することになる.

$\chi$ の值を水平軸周りの回転による遠心力とコリオリ力の比（ロスビー数）の上限值と同じであると考えて，各供 試カプセルについてロスビー数の下限值を求めると

(1) $(50 \mathrm{~m} \ell) \quad$ L/a: $3.8, \quad \chi: 3.5, \omega / \Omega>1.1$

(2) (100ml) L/a: $5.0, \quad \chi: 3.8, \omega / \Omega>1.3$

(3) $(200 \mathrm{~m} \ell) \mathrm{L} / \mathrm{a}: 5.7, \quad \chi: 4.3, \omega / \Omega>1.3$

(4) (300m $\ell) \mathrm{L} / \mathrm{a}: 5.4, \quad \chi: 5.6, \omega / \Omega>0.96$

(5) $(500 \mathrm{~m} \ell) \mathrm{L} / \mathrm{a}: 5.2, \quad \chi: 8.3, \omega / \Omega>0.63$ 
となり， $\omega$ に下限があることは説明できても, 図 11 の水平軸周りの回転数の下限值がカプセルの大きさによらず 400rpm という実験結果とは一致しない.

図 15 において白い領域はカプセルの軸方向速度が負の領域, 灰色の領域は正の領域であり，回転円筒とともに 回転する座標から見ると，かなり広い領域で，1回転する間に $\mathrm{z}$ 方向速度が正の值と負の值の間で時間変動する ことがわかる.

この $\mathrm{z}$ 方向速度の変動の大体の大きさを見積もる.座標系は図 15 と同様にとり, 流体粒子の運動を単純化して, 粒子に働く圧力抗力, 摩擦抗力影響を無視して考えてみる. 半径 $\mathrm{r}$ の円周上を角速度 $\omega$ で回転している粒子の座 標を $\mathrm{x}=\mathrm{r} \cos (\omega \mathrm{t}), \mathrm{y}=\mathrm{r} \sin (\omega \mathrm{t})$ とすると, この粒子に $\mathrm{z}$ 方向に単位体積当たりに働くコリオリカはー $2 \rho \mathrm{r} \omega$ $\Omega \cos (\omega \mathrm{t})$ となる. この粒子が自由に動けると仮定して運動方程式を立てると

$\rho \mathrm{d}^{2} \mathrm{z} / \mathrm{dt}^{2}=-2 \rho \mathrm{r} \omega \Omega \cos (\omega \mathrm{t})$ となり, これを積分して dz/dt=-2r $\Omega \sin (\omega \mathrm{t}), \mathrm{z}=2 \mathrm{r} \Omega \cos (\omega \mathrm{t}) / \omega$ を得る. 今攪拌・混合を行うためには $\mathrm{z}$ 方向の速度の振幅が $\mathrm{W}_{1 \mathrm{im}}$ 以上必要であり, 粒子の位置の振幅も $\mathrm{B}_{1 \mathrm{im}}$ 以上必要であ ると仮定すると, $2 \mathrm{r} \Omega>\mathrm{W}_{1 \text { im }}, 2 \mathrm{r} \Omega / \omega>\mathrm{B}_{1 \text { im }}$ の不等式が得られる.これより

$$
\begin{aligned}
& \Omega>W_{1 \mathrm{im}} /(2 \mathrm{r}) \\
& \omega / \Omega<2 \mathrm{r} / \mathrm{B}_{1 \mathrm{im}}
\end{aligned}
$$

の 2 式が得られて，それぞれ図 13 ，図 14 に対応して，カプセルの直径が大きくなると $\Omega$ の下限值が小さくなる こと，カプセルの直径が大きくなると $\omega / \Omega$ の上限值が大きくなることを表している. 表 1 ，図 13 ，図 14 を用い て，2r をカプセル直径として， $W_{1 \mathrm{im}}$ と $\mathrm{B}_{1 \mathrm{im}}$ を見積もると， $W_{1 \mathrm{~m}}$ は約 $0.7 \mathrm{~m} / \mathrm{s} ， \mathrm{~B}_{1 \mathrm{im}}$ は約 $0.01 \mathrm{~m}$ となる.

(1) $(50 \mathrm{~m} \ell) \quad W_{1 \mathrm{~m}}: 0.71 \mathrm{~m} / \mathrm{s}, B_{1 \mathrm{~m}}: 0.0098 \mathrm{~m}$

(2) (100ml) $\mathrm{W}_{1 \mathrm{im}}: 0.74 \mathrm{~m} / \mathrm{s}, \mathrm{B}_{1 \mathrm{im}}: 0.010 \mathrm{~m}$

(3) (200ml) $\mathrm{W}_{1 \mathrm{im}}: 0.71 \mathrm{~m} / \mathrm{s}, \mathrm{B}_{1 \mathrm{im}}: 0.011 \mathrm{~m}$

(4) $(300 \mathrm{~m} \ell) \mathrm{W}_{1 \mathrm{im}}: 0.76 \mathrm{~m} / \mathrm{s}, \mathrm{B}_{1 \mathrm{im}}: 0.0093 \mathrm{~m}$

(5) $(500 \mathrm{~m} \ell) W_{1 \mathrm{~m}}: 0.59 \mathrm{~m} / \mathrm{s}, \mathrm{B}_{1 \mathrm{~m}}: 0.0076 \mathrm{~m}$

ここでもし $\omega$ が限りなく小さいとすると， $\mathrm{z}$ 方向速度の振幅と位置の振幅は限界值以上であっても，混合・攪 䢁効果は望めない. 水平軸周りの回転数の下限が $400 \mathrm{rpm}$ であることは, $\mathrm{z}$ 方向の振動周波数が約 $6.7 \mathrm{~Hz}$ 以上必要 であることを意味していると考えられる。

以上，単純にモデル化した流体粒子について，コリオリカによってもたらされるカプセル軸方向の振動運動を 調べた. 混合・擋汼寸るためには, カプセル軸方向の速度の振幅の下限值（約 $0.7 \mathrm{~m} / \mathrm{s}$ ), 位置の振幅の下限值

(約 $0.01 \mathrm{~m}$ ), 振動周波数の下限值（約 $6.7 \mathrm{~Hz}$ ） があると仮定すると, 表 1 , 図 12 , 図 13, 図 14 の実験結果を ほぼ説明できることがわかった。

\section{文献}

(1) S.Goto, N.Ishii, S.Kida and M.Nishioka, "Turbulence generator using a precessing sphere", PHYSICS OF FLUIDS, Vol. 19, No.6(2007),pp.061705-1 -061705-4.

（2）山登将宏, 後藤晋, 堀本康文, 清水雅樹, 河原源太, “歳差運動する球体容器内に維持される界面活性剤水溶液の 乱流”，日本機械学会流体工学部門講演会講演論文集 (2012/11 京都), pp. 311-312.

（3）岩永正裕, 杉山博隆, 野田祐貴, 桐生芳樹, 原田和也, “水槽内の渦に対するコリオリ力の影響”, 日本機械学会 2011 年度年次大会講演論文集（2011），CDROM NO. G050034。

（4）岩永正裕，混合攪找装置および方法，日本国特許出願 2012-67809 (2012).

（5）数值流体力学編集委員会編, 非压縮性流体解析, 初版 (1995), pp. 93-94, 東京大学出版会. 